\title{
SAÚDE INTERFACE MEIO AMBIENTE SOB A PERSPECTIVA DA EDUCAÇÃO AMBIENTAL
}

\author{
Cassol, Paulo Barrozo ${ }^{1}$; Pimentel, Bianca Nunes ${ }^{2}$ \\ ${ }^{1}$ Enfermeiro, Mestrando em Enfermagem, Especializando do Curso de Pós-Graduação em Educação Ambiental da \\ Universidade Federal de Santa Maria, Membro do grupo de pesquisa Cuidado à Saúde das Pessoas, Famílias e \\ Sociedade Autor. Endereço eletrônico > cassolpp@gmail.com \\ ${ }^{2}$ Graduanda de Fonoaudiologia, Membro do Programa de Educação do Trabalho Saúde de Santa Maria. Co-autor \\ Endereço eletrônico pimentelbnc@hotmail.com
}

\section{RESUMO}

A preservação ambiental tornou-se um problema de saúde pública. $O$ atual modelo econômico gera riqueza, mas também gera a miséria e a degradação ambiental que repercutem na saúde humana. Trata-se de um estudo reflexivo sobre as questões ambientais e sua reflexibilidade na saúde. As universidades são os grandes pólos geradores de conhecimento, contribuindo com a educação ambiental interface saúde e o meio ambiente. A educação ambiental pode contribuir nesse processo de mudança, de preservação do meio ambiente, e assim colaborando também com a melhoria na qualidade de vida e na saúde da população.

Palavras-chave: Educação Ambiental; Meio Ambiente; Saúde.

\section{ABSTRACT}

Environmental preservation has become a public health problem. The current economic model generates wealth, but also generates poverty and environmental degradation that impact on human health. This is a reflective study of environmental issues on health and its reflectivity. Universities are the major centers that generate knowledge, contributing to environmental education interface health and the environment. Environmental education can contribute to this process of change, environmental preservation, and thus also contributing to improving the quality of life and health of the population.

Keywords: Environmental Education, Environment, Health

\section{INTRODUÇÃO}

O avanço tecnológico, em poucas décadas, gerou um desenvolvimento sem precedentes na história humana, melhorando o nível e as condições de bem estar das pessoas. Todavia, preocupou-se pouco com o impacto que esse modelo de desenvolvimento causaria no meio ambiente. São exemplos, as impermeabilizações do solo nas cidades, o lançamento de resíduos e gases, entre outros processos de degradação que repercutem na saúde humana. Dessa forma, com a demanda de recursos agrícolas, hídricos, energéticos e minerais para manter essas populações pode-se atingir condições de irreversibilidade sobre os ambientes naturais, muitas vezes ultrapassando a sua capacidade de resiliência. A reflexibilidade negativa desse sistema atinge toda a sociedade, ou seja, a economia e a saúde física e mental da população. A superação desse modelo atual de desenvolvimento constitui um novo desafio para a humanidade. Esse estudo tem 
por objetivo apontar a educação ambiental como ferramenta na preservação ambiental e sua reflexividade na saúde. Trata-se de um Estudo reflexivo e interdisciplinar, embasado na literatura especializada. Nesta perspectiva a educação ambiental tem muito a contribuir, na formação de leituras críticas sobre o meio ambiente, assim como suas relações com os processos de preservação ambiental interface promoção da saúde, pois meio ambiente e saúde são indissociáveis.

\section{DESENVOLVIMENTO}

O capitalismo baseia-se no princípio de que ganhar deve ter precedência sobre todos os outros valores. Com isso, gera-se um ambiente econômico, social e cultural que degrada a vida. Esse modelo econômico gera riqueza e fartura no mundo, mas também gera a miséria e a degradação ambiental (SOUZA; BENEVIDES, 2005).

Pela visão antropocêntrica de mundo, o homem domina a natureza e dela se utiliza. Essa visão juntamente com as imposições do capitalismo deflagrou a crise ambiental, onde os recursos naturais são utilizados de modo predatório. A preocupação com os recursos naturais teve a atenção quando surgiram os sinais de escassez. A partir desse momento, começa a surgir uma nova visão, em que não somos donos do planeta, mas que apenas fazemos parte dele (GOMES, 2006).

Na década de 1960, o mundo iniciava um novo pensamento sobre o futuro do planeta terra e da civilização humana. Com reflexões sobre os prejuízos causados pela emissão das bombas atômicas em Hiroshima e Nagasaki, assim como outros acidentes ambientais, gerando debates e manifestações diante da temática ambiental. Em 1977, foi realizado Conferência Intergovernamental sobre a Educação Ambiental em Tbilisi, na Georgia. O Brasil participou desse encontro de onde saíram as definições, os objetivos, os princípios e as estratégias para a educação ambiental, adotados em âmbito nacional e internacional. Postulou-se que a educação ambiental é essencial para a educação global, orientada para a resolução dos problemas por meio da participação de cada indivíduo e da coletividade tanto na educação formal quanto na não formal, em favor do bem-estar da comunidade humana, bem como a importância das relações naturezasociedade (SECRETARIA DE ESTADO DA EDUCAÇÃO, PR., 2008).

O meio ambiente é um sistema, no qual interagem agentes físicos, químicos e biológicos e fatores sociais, que podem exercer efeitos sobre os seres vivos (BRASIL,2004).

A grande maioria da população brasileira vive em cidades, com crescente degradação das condições de vida, refletindo em uma crise ambiental. Por conseguinte, torna-se necessário reflexões sobre formas de pensar e agir em torno da questão ambiental (JACOBI, 2003).

O perfil da saúde da população brasileira na atualidade é formado por três cenários, os quais são condicionados por diferentes contextos socioambientais. 0 primeiro cenário ocorre predominantemente às doenças cardiovasculares e neoplásicas, cuja tendência crescente nos últimos dez anos acompanha o envelhecimento da população, com o efeito de condições genéticas, de vida e trabalho, principalmente por exposições a determinados poluentes ambientais. O segundo cenário, é formado pelas doenças infecto-parasitárias, claramente determinadas pelas condições socioambientais. Enquanto no terceiro cenário, temos as situações que engloba os acidentes e as violências. Estes três cenários evidenciam os acontecimentos socioambientais como produtores de traumas, lesões e doenças, ou seja, o perfil da saúde da população brasileira. Neste contexto a Declaração de Alma-Ata para os Cuidados Primários em Saúde de 1978, trouxe um novo pensamento na caracterização do processo saúde-doença, 
incluindo nesse processo as dimensões sociais, políticas, culturais, ambientais e econômicas como componentes necessários nas ações e aos serviços de saúde (BRASIL, 2007).

A Constituição Brasileira preconiza que Todos têm direito ao meio ambiente ecologicamente equilibrado, bem de uso comum do povo e essencial à sadia qualidade de vida, impondo-se ao Poder Público e à coletividade o dever de defendê-lo e preservá- lo para as presentes e futuras gerações (BRASIL,1988).

A Lei 8.080, de 19 de setembro de 1990, preconiza que a saúde tem como fatores determinantes e condicionantes a alimentação, a moradia, o saneamento básico, o meio ambiente, o trabalho, a renda, a educação, o transporte, o lazer e também o acesso aos bens e serviços essenciais; e que os níveis de saúde da população são um meio de demonstrar como está o nível da organização social e econômica do País (BRASIL, 2006).

Nesse sentido a promoção da saúde é uma ferramenta eficaz, conforme a primeira Conferência Internacional sobre Promoção da Saúde que apresentou a Carta de Ottawa em 1986 sendo um marco histórico no sentido da saúde, abrindo novas possibilidades. Pelo qual a carta de Ottawa apresenta o processo de promoção à saúde, o qual envolve a capacitação da comunidade para atuar na melhoria da sua qualidade de vida e saúde, participando em seu controle. Para atingir um completo bem-estar físico, mental e social, os indivíduos e grupos devem saber identificar aspirações, satisfazer necessidades e modificar favoravelmente o meio ambiente. Outros elementos importantes nesse processo são pré-requisitos para a saúde como: habitação, educação, alimentação, renda, ecossistema estável, recursos sustentáveis, justiça social e equidade (Brasil, 2002 Ministério da Saúde).

O desenvolvimento da interface entre saúde e ambiente, com o intuito de implementar uma política de saúde ambiental, emerge da necessidade de aprimorar o atual modelo do Sistema Único de Saúde (SUS), de forma que a promoção da saúde seja realizada, não exclusivamente nas unidades de saúde, mas também no cotidiano da vida humana, na dinâmica da vida das cidades e do campo. Compreendendo o ambiente como um território vivo, com reflexos de processos políticos, históricos, econômicos, sociais e culturais. Nesse sentido é necessário práticas de saúde voltada para os determinantes e condicionantes da saúde (BRASIL, 2007).

No Brasil as principais ocorrências em relação à saúde humana, após as inundações, são os surtos de leptospirose, transmitida pelo contato com água ou lama contaminada pela urina de roedores contaminados. Frequentemente, as inundações levam à contaminação da rede pública de abastecimento de água e, diversas vezes, a população utiliza essa água expondo-se ao risco de ingerir bactérias, vírus e parasitas; com isto, a população poderá desenvolver doenças como a cólera, febre tifoide, hepatite A e infecções por parasitas intestinais. Quanto à dengue, posteriormente à inundação, ocorre a formação de muitos criadouros em recipientes naturais e artificiais favorecendo, dessa forma, o desenvolvimento do vetor e o aumento do índice de infestação por Aedes aegypti (BRASIL, 2011).

Os desastres naturais mais frequentes no Brasil atualmente são as inundações, com $61,8 \%$ dos registros, seguido pelos escorregamentos $15 \%$. Algumas atividades humanas que contribuem para as enchentes e as inundações são as construções de estradas, casas, prédios e outras edificações que impermeabilizam o solo. Desta forma, as águas das chuvas não são absorvidas pelo solo e escoam diretamente para os rios aumentando rapidamente seu nível. a presença de vegetação nas margens dos corpos hídricos, minimizam as taxas de erosão que causa o assoreamento dos cursos d'água; o lixo quando não tem o descarte adequado obstrui os bueiros, canais e tubulações que levariam as águas para o rio, alagando áreas que normalmente não eram invadidas pelas águas. No rio, o lixo também pode funcionar como uma represa, proporcionando o rápido aumento do seu 
nível. Para a minimização desses impactos negativos é importante que o Estado e a sociedade se preparem adequadamente com a promoção de melhorias sociais, aumento do emprego e renda; expansão do saneamento básico e o acesso à educação com qualidade, assim como uma melhor assistência na saúde. Assim como as melhorias urbanísticas que reduzam as impermeabilizações do solo e os assentamentos de comunidades em áreas de risco, pois estão sujeitas a inundações e a deslizamentos das encostas (MARCELINO; NUNES; KOBIYAMA, 2006; BRASIL, 2011; MARICATO, 2000).

A degradação e a escassez dos recursos hídricos deixaram de ser uma questão de luta de ambientalistas, tornando-se um problema de saúde pública (MORAES; JORDÃO, 2002).

O processo de crescimento das cidades gerou um aumento da contaminação do meio ambiente. Entre os diversos contaminantes a poluição do ar tem tido destaque, por atingir grande parte da população humana e possuir diversos efeitos danosos para a saúde (CASTRO; GOUVEIA; CEJUDO, 2003).

Como estratégia para reduzir as emissões de poluentes, podemos destacar, o desestímulo do uso de automóveis nas metrópoles, investindo em transportes públicos de qualidade e alternativos como o ciclismo. Na área industrial são importantes as políticas de controle e eliminação de resíduos. No campo, adotar medidas de redução de queimadas e o desenvolvimento de agricultura saudável. Para uma maior efetividade das ações de que reduzam a poluição que repercutem na saúde da população, é necessária a atuação das esferas do poder público Federal, Estadual e Municipal (CASTRO; GOUVEIA; CEJUDO, 2003).

Em enfermagem o cuidado também está relacionado com o cuidado do ecossistema, no sentido em que se busca proteger a vida do homem e da natureza. Os problemas ambientais podem refletir em problemas de saúde. Sendo possível estabelecer uma relação complexa de cuidados, por meio de uma visão integradora entre homem-natureza, saúde ambiente (BAGGIO; et al, 2011).

O meio Ambiente e saúde são indissociáveis, as relações entre os homens e o ambiente podem ser favoráveis ou prejudiciais à saúde, a sua compressão é fundamental para a promoção da saúde. Esta envolve os apoios educacionais e ambientais, mesclando os determinantes de saúde como os fatores genéticos, ambientais e sociais. Neste contexto, a educação ambiental envolve as circunstâncias sociais, políticas e econômicas onde os fatores ambientais também são considerados quando se planeja atividades de promoção à saúde (CANDEIAS, 1997).

A Educação Ambiental é um processo, onde as pessoas participam ativamente no diagnóstico dos problemas e na busca de soluções, são agentes transformadores, desenvolvendo habilidades e atitudes, por meio de uma conduta ética e condizente ao exercício da cidadania (RUIZ; LEITE; AGUIAR, 2005). É um processo de modificação, um dos caminhos para a preservação da biosfera, com a participação dos indivíduos tanto na identificação dos problemas, como na procura de soluções, portanto inserida na era globalizada (CASSOL, 2012).

Constitui-se um desafio formular uma educação ambiental que seja crítica e inovadora, tanto em nível formal como no não formal. Assim a educação ambiental deve ser um ato político voltado para a transformação social, buscando a solidariedade, a igualdade e o respeito à diferença, atuando de formas democráticas, interativas e dialógicas. Com o objetivo de formar novas atitudes, comportamentos, mudanças de valores frente ao modelo de consumo da sociedade atual (PERETTI, 2012).

É necessário criar uma "cultura voltada à saúde", feita de forma natural e eficaz, em ordem decrescente no nível educacional, ou seja, partindo das instituições de ensino superior, até as escolas de educação infantil. Práticas alternativas educacionais, como a educação ambiental na educação infantil através da contação de histórias (MOURA; CANTUARIA; BERGAMASCHI, 2001). A 
escola como cenário de práticas educativas em educação em saúde, tendo como ênfase a relação dialógica de ensino-aprendizagem (QUEIROZ; OLIVEIRA; GUIMARÃES, 2011). A utilização da mídia como veículo de informação e educação informal, bem como o estudo deste meio de forma crítica e reflexiva (SILVA; CAMPINA, 2011).

\section{CONCLUSÕES}

A Educação Ambiental pode contribuir no processo de preservação ambiental, onde as pessoas participam na busca de soluções. Sua importância é reconhecida pela constituição Brasileira, a qual declara que todos os brasileiros têm o direito à educação ambiental e o Estado o dever de promovê-la em todos os níveis de ensino.

A promoção da saúde envolve os apoios educacional e ambiental, gerando sólida construção do conhecimento e atualizações. As universidades são os grandes pólos geradores de conhecimento, tendo muito a contribuir, trabalhando a interface saúde e o meio ambiente tanto a nível acadêmico, como em projetos de extensão e em capacitação para professores ou outros profissionais. O resultado é a melhoria no ambiente e na qualidade de vida e na saúde da população.

\section{REFERÊNCIAS BIBLIOGRÁFICAS}

BAGGIO, M.A.; CALLEGARO, G.D.; LORENZINI , ERDMANN.A.L.L. reme - Rev. Min. Enferm.;15(1): 11-18, jan./mar., 2011. SIGNIFICANDO O CUIDADO ECOLÓGICO /PLANETÁRIO /COLETIVO/DOAMBIENTE À LUZ DO PENSAMENTO COMPLEXO. Disponível em http://www.enf.ufmg.br/site_novo/modules/mastop_publish/files/files_4e1dbbb6670cc.pdf.Acess o em 28/06/12.

BRASIL, 1988. Constituição Federal brasileira. Disponível em > http://www.planalto.gov.br/ccivil_03/constituicao/constitui\%C3\%A7ao.htm. Acesso em 10/07/12.

BRASIL, 2002. Ministério da Saúde. Disponível em > http://bvsms.saude.gov.br/bvs/publicacoes/cartas_promocao.pdf. Acesso em 20/05/12.

BRASIL, 2004. Instituto Brasileiro de Geografia e Estatística - IBGE. VOCABULARIO BASICO DE RECUSOS NATURAIS E MIO AMBIENTE. 2. EDIÇÃO. Rio de Janeiro 2004 . Disponível em: http://www.ibge.gov.br/home/presidencia/noticias/vocabulario.pdf. Acesso em: 14/06/12.

BRASIL, 2006. MINISTÉRIO DA SAÚDE. Disponível em http://conselho.saude.gov.br/biblioteca/livros/coletanea_miolo.pdf. Acesso em 30/06/12.

BRASIL, 2007. Brasil. Ministério da Saúde. Conselho Nacional de Saúde.Subsídios para construção da Política Nacional de Saúde Ambiental / Ministério da Saúde, Conselho Nacionalde Saúde. Brasília: Editora do Ministério da Saúde, 2007. Disponível em >http://conselho.saude.gov.br/biblioteca/livros/subsi_miolo.pdf. Acesso em 11/060/12. 
BRASIL, 2011. Ministério da Saúde. Guia de preparação e resposta aos desastres associados às inundações para a gestão municipal do sistema único de saúde. Disponível em http://portal.saude.gov.br/portal/arquivos/pdf/guia_sms_desastres_jan2011_2.pdf. Acesso em 24/06/12.

CANDEIAS, N. M.F. Conceitos de educação e de promoção em saúde:

mudanças individuais e mudanças organizacionais. Rev. Saúde Pública vol. 31 no. 2 São Paulo Apr. 1997doi: 10.1590/S0034- 89101997000200016.Disponível em: http://www.scielo.br/scielo.php?script=sci_arttext\&pid=S0034-89101997000200016

Acesso em: 04/06/12.

CASSOL. O VERDE ABALOU O MURO. Revista Eletrônica em Gestão, Educação e Tecnologia Ambiental. Vol. 5, No 5. p.767-772 (2012). Disponível em: http://cascavel.ufsm.br/revistas/ojs2.2.2/index.php/reget/article/viewFile/4211/2805. Acesso em 06/05/12.

CASTRO, H.A.GOUVEIA, N. CEJUDO, J.A.E. Questões metodológicas para a investigação dos efeitos da poluição do ar na saúde. Rev. Bras. Epidemiol. Vol. 6, № 2, 2003. http://www.scielo.br/pdf/rbepid/v6n2/07.pdf. Acesso em: 04/06/12.

GOMES, D.V. Algumas considerações sobre o desenvolvimento sustentável. Educação ambiental em ação. No. $18 \quad$ - $\quad 01 / 09 / 2006$ Disponível em > http://www.revistaea.org/artigo.php?idartigo=427\&class=20. Acesso em 20/06/12.

JACOBI, P. Educação Ambiental, Cidadania e Sustentabilidade Cadernos de Pesquisa, n. 118, mp. a1rç809/- 220050,3 março/ $2003 \quad 189 . \quad$ Disponível em > http://www.scielo.br/pdf/cp/n118/16834.pdf. Acesso em 02/06/12.

MARCELINO, E.V.; NUNES, L.H.; KOBIYAMA, M. Banco de dados de desastres naturais: análise de dados globais e regionais. Caminhos de Geografia. Uberlândia v. 6, n. 19 out/2006 p. 130-149. Disponível em: http://www.inpe.br/crs/geodesastres/conteudo/artigos/Marcelinoetal_2006_Banco_de_dados_de_desastres_naturais.pdf. Acesso em: 28/06/12

MARICATO, E. Urbanismo na periferia do Mundo Globalizado metrópoles brasileiras. São Paulo Perspec. vol.14 no.4 São Paulo Oct./Dec. 2000.Disponível em: http://www.scielo.br/scielo.php?pid=S0102-88392000000400004\&script=sci_arttext. Acesso em: $20 / 06 / 12$

MORAES, D.S.L . JORDÃO, B.Q. Degradação de recursos hídricos e seus efeitos sobre a saúde humana. Rev Saúde Pública 2002;36(3):370-4. Disponível em: http://www.scielo.br/pdf/rsp/v36n3/10502.pdf. Acesso em: 20/06/12 
MOURA, G. M; CANTUARIA, J. J. M.; BERGAMASCHI, E. M. M.; EDUCAÇÃO AMBIENTAL A PARTIR DE CONTAÇÃO DE HISTÓRIA NA EDUCAÇÃO INFANTIL. Anais dos Simpósios da Pedagogia UFG-CAC;
V.11,
N.1;
2011;
pp.95-102
Disponível

em:http://educacao.catalao.ufg.br/publicacoespedagogia/index.php/simposiopedago/article/view/ 73. Acesso em: 28/06/12

PERETTI, V.A. EDUCAÇÃO AMBIENTAL NA ESCOLA PÚBLICA: O CASO DA E. E. E. F. JOSÉ FERREIRA RAMOS - GAURAMA/RS. Revista Eletrônica em Gestão, Educação e Tecnologia Ambiental v(5), $\mathrm{n}^{\circ} 5$, p. 841 - 849, 2012.. Disponível em : http://cascavel.cpd.ufsm.br/revistas/ojs2.2.2/index.php/reget/article/view/4246/2814. Acesso em: 28/06/12

QUEIROZ E. D.; OLIVEIRA, A. L.; GUIMARÃES, M. PRÁTICAS EDUCATIVAS EM EDUCAÇÃO AMBIENTAL A PARTIR DO DIÁLOGO ESCOLA-COMUNIDADE. Revista Pesquisa em Educação Ambiental, vol. 6, n. 1 - pp. 29-46, 2011. Disponível em:http://www.periodicos.proped.pro.br/index.php?journal=revistateias\&page=article\&op=view\& path\%5B\%5D=702 Acesso em: 28/06/12

RUIZ, J. B.; LEITE, E. C.; RUIZ, A. M.; AGUIAR, T. F. Educação Ambiental e os temas transversais. Revista de Ciências Humanas da UNIPAR. Akrópolis, Umuarama, v.13, no.1, jan/mar., 2005. Disponível em: http://revistas.unipar.br/akropolis/article/view/451/410. Acesso em 15/09/11

SECRETARIA DE ESTADO DA EDUCAÇÃO. Superintendência de Educação. Departamento da Diversidade.Coordenação de Desafios Educacionais Contemporâneos. Curitiba : SEED- PR., 2008. Disponível em > http://www.agraçadaquímica.com.br/quimica/arealegal/outros/135.pdf\#page=15. Acesso em 03/06/12.

SILVA, R. L. F. DA; CAMPINA, N. N. Concepções de educação ambiental na mídia e em práticas escolares: contribuições de uma tipologia. Revista Pesquisa em Educação Ambiental vol. 6, n. 1 pp. 29-46, 2011. Disponível em: http://www.revistasusp.sibi.usp.br/scielo.php?pid=S198011652011000100003\&script=sci_arttext. Acesso em: 28/06/12

SOUZA, J.N.S.; BENEVIDES, R.C.A. Educação Ambiental Para o Desenvolvimento Sustentável e o Comprometimento dasUniversidades/Faculdades do Município do Rio de Janeiro, RJ. II Simpósio de Excelência em Gestão e Tecnologia - SEGeT'2005. Disponível em > http://www.aedb.br/seget/artigos05/343_artigo.pdf. Acesso em 04/11/11. Acesso em 03/06/12. 